\title{
¿ESPACIO DE CONSUMO O CONSUMO DEL ESPACIO? EL CASO DE PALO ALTO MARKET, BARCELONA
}

\author{
José A. Mansilla \\ Observatori d'Antropologia del Conflicte Urbà (OACU) \\ Grupo de Investigación Interdisciplinar en Turismo (GRIT) - Ostelea, Escuela Universitaria de Turismo \\ Universitat de Lleida \\ Email: jamansilla@ostelea.com
}

\section{Resumen}

Las ciudades han pasado de ser el escenario privilegiado para la reproducción social, a convertirse en verdaderos espacios de y para el consumo. Las políticas neoliberales han empujado a ciudades como Barcelona a dejar atrás su pasado industrial y abrazar un proceso de terciarización que supone una potente metamorfosis local, no solo en su carácter productivo, sino también en su entramado urbano. Los antiguos mercados de abasto, así como otros de nueva creación, se muestran como auténticos epicentros de estas prácticas mercantilizadas, deviniendo centros de consumo y de ocio. Palo Alto Market, en el barrio barcelonés del Poblenou, se caracteriza por su apuesta por la sofisticación, así como por su inigualable emplazamiento. Sin embargo, tras una apariencia cargada de potentes recursos simbólicos que lo hacen único en la ciudad, podrían esconderse prácticas y relaciones de dominación, además de actuar como vanguardia en las transformaciones socio-espaciales de su entorno más inmediato.

\section{Palabras clave}

Mercados, ciudades, consumo, capital cultural, violencia simbólica

\begin{abstract}
Cities have gone from being the privileged scenario for social reproduction, to become spaces of and for consumption per excellence. Neoliberal policies have been pushing cities like Barcelona to leave behind its industrial past and embrace a process of terciarization, which has generated a potent local metamorphosis, not only in its productive nature, but also in its urban fabric. The ancient food markets and other newly created are shown as real epicentres of these commodified practices, becoming centres of consumption and leisure. Palo Alto Market, in the Barcelona's neighbourhood of Poblenou, is characterized by its commitment to sophistication, as well as its great setting. However, the powerful symbolic resources that make it unique in the city could hide practices and relationships permeated by domination. Furthermore, Palo Alto Market could be acting as a vanguard in the socio-spatial transformations that its immediate surroundings are witnessing.
\end{abstract}

\section{Key words}

Markets, cities, consumption, capital, cultural, symbolic violence 


\section{INTRODUCCIÓN ${ }^{1}$}

En este artículo analizaré uno de los mercados urbanos que existen actualmente en Barcelona como elemento representativo de los cambios ocurridos en la ciudad a lo largo de los últimos años; procesos que han conllevado la desaparición de la potente actividad industrial de la que hizo gala la ciudad desde mediados del siglo XIX (Tatjer, 2006; Nel·lo y Donat, 2014), a consecuencia de la implementación de una serie de políticas de fomento del sector terciario, principalmente turístico, pero también inmobiliario, comercial, tecnológico y/o financiero, y que, aunque sitúan a Barcelona como laboratorio de prácticas neoliberales, no dejan de ser comunes a otras ciudades de Europa y Latinoamérica (Harckworth y Smith, 2001; Harvey y Smith 2005; Delgado, 2005 y 2007; Recio, 2009; Llistar, 2015; Leal, 2016).

A partir del ejemplo de Palo Alto Market, y mediante la reconstrucción del discurso y del contexto en el cual se ubica, me propongo reflexionar acerca de la realidad de este tipo de emplazamientos y del papel que juegan en la Ciudad Condal. Así, me gustaría partir de la siguiente hipótesis: la celebración de un evento como Palo Alto Market encaja perfectamente en la dinámica de terciarización y turistificación que viene viviendo la capital catalana, y el barrio donde se enclava -el Poblenou-, desde hace décadas, contribuyendo a su reproducción; el estudio de este mercado permite, además, mostrar que tras un relato plegado de referencias a formas de consumo ciertamente elitistas destinado a públicos exclusivos, se encuentran formas de dominación y (auto)explotación, impactando en su entorno y generando efectos miméticos en su contexto más inmediato, así como contrapropuestas populares desde posiciones no hegemónicas.

En la primera parte del texto, fruto de una investigación etnográfica llevada a cabo a lo largo del primer semestre de 2016, se realiza un breve recorrido por la historia reciente de Barcelona y del barrio del Poblenou, trazando las líneas generales y destacando los principales protagonistas del proceso de desindustrialización que ha vivido la ciudad, así como su encaje, vía sector terciario, en el marco general del capitalismo internacional (Castells, 1995). En la segunda parte se propondrán algunas ideas y referencias de carácter teórico y práctico en torno a este tipo de espacios, los efectos que generan en su entorno más próximo y las estrategias de dominación y reproducción desarrolladas a través de su despliegue simbólico. En la tercera parte se presenta el caso etnográfico, el citado Palo Alto Market, como ejemplo representativo de mercado al servicio del proceso de acumulación en contextos urbanos, aunque con características peculiares. Y, por último, se propone un análisis y una discusión del mismo en base al marco presentado.

\section{2. ÉRASE UNA VEZ UNA CIUDAD}

Desde los primeros Gobiernos socialistas de la ciudad tras la Transición, Barcelona ha buscado posicionarse a nivel internacional como una ciudad repleta de significados y símbolos que la hicieran atractiva, destacando, para ello, el papel jugado por el diseño urbano y la arquitectura (Moix, 2002; Lahuerta, 2005; Galtés, 2016). Sin embargo, la historia de Barcelona como ciudad global (Sassen, 1999) viene de lejos. Si bien, el lanzamiento definitivo de la capital catalana se produjo con su designación, en 1986, como sede de los Juegos Olímpicos (JJOO) de 1992, ya en décadas anteriores, en pleno Franquismo y bajo la alcaldía de Josep Maria de Porcioles, la estrategia del Ayuntamiento, así como de otros niveles de la administración, pasaba por proyectar Barcelona, a nivel internacional, como "ciudad de ferias y congresos". ${ }^{2}$ Cabe recordar que fue el mismo Porcioles el que dio los primeros pasos hacía la profunda terciarización que vive ahora la ciudad (Marrero, 2003) cuando propuso transformar aquellas partes del entramado urbano que alojaban la mayor concentración de tejido industrial (Mansilla, 2014), el barrio del Poblenou, en el actual Distrito de Sant Martí, en una "Copacabana barcelonesa".3

Desde entonces, Barcelona ha crecido, cambiado su fisionomía y diversificado su economía casi a golpe de mega-evento (Capel, 2005; Mascarenhas, 2010; Makhlouf, 2015a). Desde el Congreso Eucarístico de 1952; pasando por los intentos frustrados de celebrar una Exposición Universal en 1982; la propia celebración de los JJOO; el fracaso de convertirse en Capital Cultural Europea para 2001; hasta llegar al último y más controvertido, el Fòrum de les Cultures $2004,{ }^{4}$ la ciudad ha completado, de esta manera, su transformación, pasando de acoger un Manchester catalán (Marrero, op. cit.), a convertirse en un referente turístico de nivel planetario.

\footnotetext{
${ }^{1}$ Este texto es una versión de un artículo enviado para su evaluación a la Revista de Antropología Social

2 Véase El Diario de Barcelona, 11 de diciembre de 1959, pag. 5. y el vídeo de promoción titulado "Barcelona ciudad de congresos" (1970) https://www.youtube.com/watch?v=MiRBI LXgSY

${ }^{3}$ Véase El País, 19 de noviembre de 1999.

${ }^{4}$ El objetivo de convertirse en Capital Europea de la Cultura no se llegó a alcanzar. Sin embargo, esto llevó a la ciudad a crear una cita internacional -el Fòrum- de la nada. Véase, El País, 9 de mayo de 2004.
} 
Este proceso, sin embargo, no es único de la capital catalana. Además de otras ciudades del Estado, así como del resto de Europa, el cercano ámbito de su área metropolitana ${ }^{5}$ también ha sido protagonista de un proceso similar que se acentuó con el estallido de la burbuja inmobiliaria a partir del 2008. La destrucción de la ocupación que trajo consigo la crisis fue más pronunciada en el sector industrial de esta zona, además de en la construcción, haciendo que el impacto social ocasionado haya sido enormemente gravoso en términos de desigualdad social (Porcel, Sarasa y Navarro-Varas, 2015).

Barcelona es hoy una ciudad con 1.604.555 habitantes (INE, 2015) y una tasa de ocupación del 69,2\%, donde la población que trabaja en el sector servicios supone más del $89 \%$ del total, mientras que los ocupados en la industria y la construcción representan únicamente un 8 y un $3 \%^{6}$, respectivamente (Ajuntament de Barcelona, 2015a). ${ }^{78}$

La ciudad, así, se ha convertido en polo de atracción de eventos y capitales a nivel internacional y prueba de ello es la celebración de los numerosos acontecimientos de renombre (Smart City Expo, World Mobile Congress, etc.) que la insertan en las redes del capitalismo global, así como el alto número de pernoctaciones turísticas anuales -más de 17 millones, si contabilizamos únicamente los hoteles-, y el incremento del número de este tipo de establecimientos, que se han duplicado en los últimos 15 años. ${ }^{9}$ Como señala el antropólogo Marc Dalmau (2016: 83),

[...] a día de hoy, independientemente de la periodicidad de los grandes eventos internacionales, la ciudad intenta incrementar el ritmo de circulación del capital a partir de la organización de microeventos periódicos que cumplirían la función de atraer la inversión cotidianamente: congresos, ferias de muestras, exposiciones culturales, competiciones deportivas y eventos de todo tipo.

Esta nueva orientación del carácter social y económico de Barcelona ha desencadenado ciertas dinámicas que han acabado por transmutar su configuración socio-espacial, con la consecuente aparición de una conflictualidad urbana muy marcada vinculada, sobre todo, a procesos de gentrificación, turistificación, desaparición del comercio tradicional, privatización del espacio urbano, etc. (Cocola, 2015; Makhlouf, 2015b; Hernández y Tutor, 2015), poniendo en evidencia su mercantilización (Harvey, 2007a, 2007b y 2008; Brenner, Peck y Theodore, 2015) y dando lugar a la aparición de una ciudad convertida, básicamente, en un "escenario para el consumo" (Tello, 1993: 507).

En este contexto, el barrio del Poblenou ha sufrido algunas de las transformaciones más importantes de las últimas décadas. A las ya citadas -la creación de la Vila Olímpica y la celebración del Fòrum de les Cultures, ejecutadas en su territorio- habría que añadir el intento de creación de un distrito tecnológico, el 22@, a través de la modificación del Plan General Metropolitano del año 1976. La idea de alcanzar el sueño de un "SoHo barcelonés" (Marrero, op. cit.), actuando sobre 116 hectáreas del Poblenou, partió del Ayuntamiento de Joan Clos, siendo puesto en marcha a partir del año 2000. Tal y como señalan los documentos oficiales del consistorio catalán, el objetivo era convertir el barrio en "la principal plataforma económica y tecnológica de Barcelona, Catalunya y España" (Ajuntament de Barcelona, 2000). Sin embargo, tal y como demostraron Charnock et al (2014), muchos de los desarrollos inmobiliarios llevados a cabo en el 22@ se basaron en la venta de edificios que no tenían una garantía última de ser ocupados y que, además, tampoco contaban con una definición clara sobre qué tipo de actividad se entendía como relacionada con las tecnologías y la economía del conocimiento. Esto llevó, según dichos autores, a que solo el 30\% del suelo ocupado en el 22@ en el año 2005 estuviera bajo el paraguas de las nuevas tecnologías, mientras que hasta el $72 \%$ lo copaban hoteles y empresas vinculadas a los seguros, los servicios financieros y el marketing.

\footnotetext{
${ }^{5}$ El Área Metropolitana de Barcelona (AMB), constituida por la Ley 31/2010, de 3 de agosto, del Área Metropolitana de Barcelona, está conformada por 36 municipios, $636 \mathrm{~km} 2$ y, aproximadamente, una población de 3,2 millones de personas. Para más información ver: http://www.amb.cat/s/home.html

${ }^{6}$ A modo de comparación, la otra gran ciudad del Estado, Madrid, con 3.165.883 habitantes, contaba con una tasa de actividad del $61,62 \%$, donde el $88,9 \%$ de la población estaba ocupada en el sector servicios, un $7,2 \%$ en la industria y un $3,9 \%$ en la construcción (2015).

Según la misma fuente, tan solo 14 años antes, el porcentaje de población activa dedicado a la industria era del $15 \%$, casi el doble.

${ }^{8}$ Entrando en detalle, si nos centramos, dentro del terciario, en lo referente al ámbito turístico, los datos nos muestran que entre un $7,7 \%$ y un $12,9 \%$ de la población activa, dependiendo de la fuente que se utilice, se dedica a la misma (Ajuntament de Barcelona, 2015b).

${ }_{9}$ El número total de reuniones (congresos, jornadas, convenciones, etc.) que se celebran actualmente en la ciudad es de 2.268 , cuando solo hace 25 años era de 273 (Ajuntament de Barcelona, 2015b).
} 
Finalmente, el Poblenou ha acabado convirtiéndose en uno de los enclaves más representativos de la terciariación que vive la ciudad. Así, a la revitalización que parece estar viviendo el 22@ (Benvenuty y Guerrero, 2016), se añadiría la presión del sector turístico y de la restauración, ya que en la actualidad el barrio acoge unas 12 mil plazas hoteleras y cuenta con otras 3 mil en construcción, a lo que habría que añadir unos 700 pisos turísticos (Mansilla, 2016). Además, algunos de sus principales espacios de socialización, como la Rambla del Poblenou, han vivido a lo largo de los últimos años un creciente proceso de ocupación por parte las terrazas de bares y restaurantes, algo que ha obligado al Ayuntamiento de la ciudad a realizar una ordenación singular del entorno (Ajuntament de Barcelona, 2013)

\section{LOS MERCADOS URBANOS COMO ESPACIOS SIMBÓLICOS DE CONSUMO}

Tal y como señalaran Lees et al (2008), los aspectos simbólicos juegan un papel cada vez más destacado en la generación de espacios de consumo, así como en las dinámicas de mercantilización y revalorización de lo urbano que viven las ciudades. En este sentido, los mercados contarían con connotaciones y atributos que los hacen altamente legibles y significativos. Desde hace unos años se están llevando a cabo interesantes trabajos que abundan, principalmente, en la relación entre los antiguos y populares mercados de abasto, ahora transformados en zonas que cuentan con tiendas exclusivas de productos de alto precio y locales de diseñadores, y procesos como la gentrificación y la turistificación de las áreas donde éstos se hallan enclavados. En este sentido podemos hablar del estudio pionero del Mercado de Kirkgate, en Leeds (Inglaterra), estudiado por González y Waley (2013), del Mercado de Santa Caterina, en Barcelona, España, (Hernández, 2014), del estudio llevado a cabo por Rodríguez (2016) en los mercados de San Miguel y San Antón, en Madrid, España, de la comparación entre el proceso madrileño y el que se vive en algunas ciudades de Latinoamérica, como Quito, Ecuador, (Grad, 2016) y, ya fuera del ámbito de estos mercados más tradicionales, de la investigación realizada sobre el Mercado de Motores, también en Madrid, por Adreeva (2016).

Así, en el ámbito más cercano del Estado español, y a juzgar por la bibliografía consultada y señalada, sería posible destacar las diferentes orientaciones que ciudades como Barcelona y Madrid están tomando en este ámbito (Rodíguez, op. cit.) y donde la ciudad catalana parece mantener, con la excepción del citado Mercado de Santa Caterina y el del Born, el carácter y el uso de estos tradicionales emplazamientos (Instituto de Mercados de Barcelona, 2012), mientras que la capital estatal apuesta por la innovación y su modernización y apertura a otros públicos (Móvil, 2016).

Todos estos estudios exploran la relación entre estos espacios -su transformación y su nuevo papel en el paisaje urbano-, con las dinámicas de cambio social y espacial que generan a su alrededor. Sin embargo, el objeto del presente texto no es tanto abundar en este sentido sino analizar, más bien, cómo este tipo de instalaciones elaboran y difunden una serie de relatos y narraciones que permiten la aceptación de dichas metamorfosis, aun siendo, en ocasiones, perjudiciales, debido a los efectos producidos para sus protagonistas más inmediatos. En definitiva, me propongo examinar el aparato simbólico que permite su reproducción y encaje en el contexto de la terciarizada Barcelona contemporánea en línea con lo que otros autores (Guano, 2002 y 2004; Carman, 2006) han venido trabajando para otras ciudades y donde determinadas clasificaciones de orden cultural y social, siempre originadas externamente a los sectores dominados, son reconocidas por estos como legítimas y utilizadas para ubicar su propia posición en la ciudad.

En su trabajo La distinción. Criterio y claves sociales del gusto ([1979] 1998), Pierre Bourdieu explicaba que son precisamente los criterios mediante los que externalizamos, entre otras cuestiones, nuestro gusto personal, aquellos que nos permiten identificarnos y adherirnos a las formas o niveles en los que se encuentran divididas las producciones estéticas, intelectuales, corporales, etc. Como no podía ser de otra manera en un autor como Bourdieu, estos niveles servirían, por un lado, para establecer una clasificación clara y precisa de la sociedad a través de sus componentes de clase pero, al mismo tiempo, serían capaces de constituir un sistema adscriptivo autónomo a partir de sus propias características, de forma que admitiría clasificar(se) a los individuos en función de una serie de niveles culturales identificables. Este orden simbólico reconocido y de prestigio -que el sociólogo francés adjudica en dicha obra a las certificaciones académicas- otorga, a los que entran en contacto con él, consideraciones de legítima posesión de un capital cultural que permite, no solo el establecimiento de jerarquías, sino la reproducción del mismo por medio de su aceptación por parte de los participantes.

Sin embargo, sería imposible desligar las propiedades que caracterizan a los individuos y los grupos sociales del tiempo y el espacio social en el que se desarrollan. De este modo, no podemos dar por fijas o 
inscritas en la esencia de los sujetos determinadas preferencias o comportamientos, ya que estos siempre estarían determinados mediante un espacio social e históricamente constituido, en definitiva, por cierto número de relaciones de orden basadas en dos variables principales: el capital económico -la clase- y el capital cultural. Así, la posesión de una cantidad suficiente de estos capitales específicos permitiría ocupar posiciones dominantes en el espacio en cuestión. La conservación o transformación, a través de una tasa de cambio, de dichos capitales, determinaría las luchas que se producen entre individuos y/o grupos, de forma que la dominación de unos sobre otros no se ejercería de forma coactiva, sino, más bien, con el consentimiento de los dominados que se ven inmersos en esa completa red de relaciones conflictivas (Bourdieu, [1994] 1997; Weber, [1922] 2002).

De este modo, y en relación al objeto de estudio, la apropiación de los recursos simbólicos proyectados por los mercados antes reseñados, casi siempre originados y orientados a consumidores de gustos refinados, sofisticados y de alto poder adquisitivo, permitiría, a los individuos y los grupos del espacio social de Barcelona, participar de un capital cultural que los resituaría en dicho espacio, a la vez que, mediante la aceptación de la violencia simbólica (Ibíd.) sobre ellos ejercida, consentirían una dominación bajada en la legitimidad antes referida (Weber, op. cit; Bourdieu y Wacquant, [1992] 2005)

Desde una perspectiva diferente, estos mercados supondrían elementos de aquello que Manuel Castells denominara ideología urbana ([1972] 1974), es decir, aquella que organiza el espacio conformándolo como una red de carácter simbólico, y que "legitima [...] y racionaliza ciertos intereses 'a fin de presentar su dominación como expresión de un interés general' y, simultáneamente, comunica [...] para que los ciudadanos compartan un mismo código" (González, 1998: 314). Estaríamos, de este modo, y no pudiendo ser de otra manera teniendo en cuenta la formación inicial de Castells, en aquello que Althusser (1969) denominara aparatos ideológicos del Estado, y donde la cultura y sus instituciones formarían parte esencial ejerciendo una represión "muy atenuada, disimulada, es decir, simbólica".

\section{PALO ALTO MARKET}

El Mercado de Palo Alto, o Palo Alto Market, como se promociona el lugar, se encuentra enclavado en el barrio del Poblenou, Barcelona. Se trata de un recinto cerrado que acoge un conjunto de edificaciones, antiguamente industriales, cuyo origen se remonta al año 1875, cuando los empresarios Ramón Gal y Joan Puigsech ordenaron su construcción con el objeto de poner en marcha una fábrica textil. A lo largo de los años, el perímetro se fue completando con otras industrias (fabricación de sémolas, féculas y glucosa), hasta que en 1940 pasó a acoger un pequeño número de empresas que se repartieron por las edificaciones levantadas. A finales de la década de los 80 , un empresario francés adquirió la totalidad del conjunto con la idea de crear unos estudios de cine bajo el nombre de Palo Alto, proyecto que fracasaría, aunque la idea de dedicar el reciento a cuestiones culturales se mantiene, incorporando al diseñador Mariscal -famoso creador de la mascota olímpica Cobi- que instalaría ahí su estudio. Con la llegada de los JJOO en 1992, el espacio es inicialmente afectado por los planes urbanísticos para la zona, aunque tras una serie de vicisitudes, logra salvarse. Tanto Mariscal como otros inquilinos constituyen, en el año 1997, la Fundació Privada Centre de Producció Artística i Cultural Palo Alto, que mantiene el espíritu original de promover y gestionar iniciativas artísticas y culturales (Fabre y Huertas, 1976; Domínguez Sensada, 2012).

Desde entonces, el recinto comparte la actividad de los diseñadores, arquitectos y artistas allí ubicados (hasta 17 según su web, www.paloaltobcn.org), con la existencia de una cantina y una serie de espacios comunes -jardines y áreas polivalentes- que son alquilados y/o cedidos para el desarrollo de acciones diversas, tales como rodajes cinematográficos y publicitarios, celebración de exposiciones y otros eventos acordes al objetivo inicial de la Fundación. Aunque el nombre de Mariscal sigue ligado a Palo Alto -la idea del Mercado parte de miembros de su familia, y él sigue participando en la Fundación- el diseñador, debido a cuestiones económicas, tuvo que cerrar su estudio en 2014 (Antequera, 2015).

Es así como, en diciembre de ese mismo año, se celebra la primera edición de Palo Alto Market, un mercado que, en palabras de su Directora, Paula Mariscal, sobrina del creador de Cobi,

[...] es un mercado diferente de los que hay en la ciudad, que son muchos, y están muy bien, fantásticos [...] pero que están centrados en el vintage y en el second hand..., así Palo Alto dice, 'esa parte ya está cubierta', pero continua habiendo un potencial dentro del formato mercado que no se está cubriendo, que es el de un mercado más sofisticado, con una oferta más diversa y 
que contempla temas que la ciudad de Barcelona, con todo el potencial de talento y diseño que tiene, se estaba quedando sin tener una plataforma (sic) [...] que parece que hace falta. ${ }^{10}$

Desde esa primera edición, cada primer fin de semana de mes, el mercado ha venido celebrándose ininterrumpidamente en el interior del recinto de Palo Alto, contando, además, con una alta repercusión mediática. ${ }^{11}$ El éxito de la primera edición fue tal que, debido a las llamadas de los vecinos a la Guardia Urbana de Barcelona ante la sorpresa por la aglomeración de gente, ésta se vio obligada a cerrar el recinto tras realizar una breve inspección y comprobar que el evento no disponía de las licencias necesarias (EI Mundo, 2014). Tras solucionar el incidente, el primer fin de semana de enero de 2015, Palo Alto Market volvió a abrir con toda la documentación en regla, pero cobrando una entrada de dos euros, en un intento por evitar las aglomeraciones.

Entre los adjetivos e imágenes que identifican, en prensa, redes sociales y otros medios de expresión (Come Calles, 2015; @PaloAltoMarket), la propuesta del mercado objeto bajo investigación, es posible encontrar siempre expresiones como "cultura alternativa", "ocio familiar", "sofisticación", "consumo responsable", "creatividad", "artistas emergentes", "referente turístico", "street food", "diseño, "food truck", "gastronomía callejera", "innovación", "emprendimiento", etc., toda una serie de nociones que, en definitiva, como señalara Manuel Delgado (2014), incidirían en la ya señalada idea de los aparatos ideológicos althusserianos, usados por las clases dominantes para obtener sus fuentes de legitimidad.

\subsection{El interior ${ }^{12}$}

Pese a las precauciones tomadas por la organización del mercado, si hubiera que destacar algo en una primera aproximación a Palo Alto, esto podría ser las colas que se forman a la hora de la entrada. En mis visitas, excepto cuando éstas han sido llevadas a cabo los sábados en horario de tarde, entre 25 y 100 personas se encontraban ya esperando para entrar al recinto. La magnitud de las filas creadas, recogido incluso por la prensa como fue señalado anteriormente, ha sido motivo continuo de quejas y reproches a la organización. Así, en las reseñas que los visitantes han escrito en redes sociales como google.com y Facebook.com encontramos frecuentes alusiones a "cosas que deben mejorar, como las colas inmensas para entrar", "horas de cola si no estás por lista", "mucha gente, colas kilométricas desde el minuto uno antes de entrar. Colas para entrar, colas para comer, colas para beber...", "la organización un CERO, te hacen hacer una cola, por aforo completo y hasta que no salen cien personas no entran cien", o "cola de media hora para pagar la entrada". En mis tiempos de espera también he sido partícipe de comentarios similares. Así, en una de las visitas, fui testigo de cómo uno de los miembros de una pareja, de unos 40 años de edad aproximadamente y recién llegada a la cola, preguntó a su acompañante al ver la misma, "uff, vaya cola, ¿merece la pena esperar?".

Otro de los frecuentes motivos de reclamación por parte de los asistentes ha sido el hecho de tener que pagar una entrada cuyo precio ha ido variando desde el inicio, dos euros, pasando por tres euros durante la realización del trabajo de campo, hasta llegar a los cuatro euros a la hora de la redacción del presente artículo (septiembre 2016). Así, en las redes sociales antes citadas también ha sido posible toparse con observaciones como "me parece excesivo el precio de la entrada, costando lo que cuesta comer dentro", "no entiendo para que [hay que pagar] ya que con lo que pagan los expositores creo que es suficiente para los gastos del evento", o "lo de que cobren entrada es como pagar 3 euros para entrar en Corte Inglés (sic)". Sin embargo, también es posible encontrar comentarios que valoran de forma distinta el hecho de este pago como "los que criticáis los 3 euros de entrada, ¿en vuestro negocio lo regaláis todo?" o la respuesta obtenida en una de las entrevistas realizadas durante la investigación, la cual señalaba que "a veces hay sitios más caros donde hay que pagar mucho más, y también entras a consumir. Por ejemplo, estos días es el Barcelona Beer Festival, en el Museu Marítim, y la entrada son 8 euros y solo tienes derecho a tomarte dos cervezas", algo que podría indicar hasta qué punto ha sido aceptado un ocio mercantilizado en la ciudad (Capel, 2013).

\footnotetext{
${ }^{10}$ Traducción propia del catalán. Para más información ver: https://www.youtube.com/watch?v=TpTVIzmO3sc

11 El Mundo, 05/12/2014, 07/12/2014, 30/06/2015; El País, 06/12/2014, 06/07/2015, 11/07/2015; La Vanguardia, 06/02/2015, 06/03/2015, 26/06/2015, TV3, 09/12/2014.

${ }_{12}$ Para el trabajo de campo llegado llevado a cabo entre enero y junio de 2016 utilicé, principalmente, la técnica de la observación participante en una serie de visitas realizadas cada uno de los fines de semana en los que el mercado estuvo abierto, en distintos horarios y días. A su vez, ésta se vio complementada con entrevistas, diálogos informales y cuestionarios, además del seguimiento y la revisión de bibliografía especializada, artículos de prensa, webs y redes sociales y visitas al mercado y su entorno fuera de los días de celebración.
} 


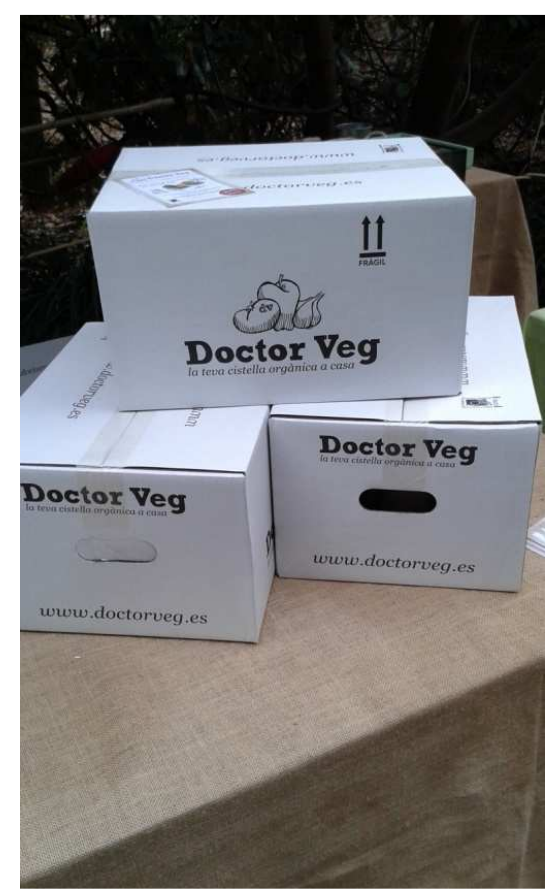

Foto 1.- Cajas exhibidas en alguna de las paradas que ocupan las calles internas de Palo Alto Market. Foto del autor.

Una vez dentro del recinto, cuyo aforo máximo es de 1.050 personas, y tras el pago de la entrada, la propia distribución del espacio te obliga a tomar la decisión de encaminarte o bien hacia la derecha, donde se encuentra la zona de restauración con los food-trucks, conocida como Food street o, a la izquierda, al área más comercial, de nombre Palm market. A lo largo de mis diferentes visitas he visto como el número de food-trucks aparcadas en esta calle ha pasado de las 9 observadas en enero, a únicamente 6 en junio. La reducción de la presencia de este tipo de negocio en Palo Alto podría ser debida a la escasa rentabilidad que generan. Así, tal y como rezaba un artículo publicado en el diario El País en julio de 2016, estos camiones rodantes no acaban de cuajar como modelo de negocio y, los más de 300 registrados a esa fecha en el Estado español, se resentían debido a su falta de viabilidad económica (Carrizosa, 2016). Entre los problemas que aducen los gestores de food-trucks se encuentran la falta de una legislación adecuada que les permita vender en la calle -ahora mismo solo lo pueden hacer en eventos privados, como Palo Alto Market- y los altos precios que cobran los organizadores de los lugares a donde acuden, lo que reduce sensiblemente sus márgenes. Además, también existen quejas de que, en ocasiones, son usados como referentes atractivos por parte de los organizadores que pretenden, de esta manera, conquistar a una mayor cantidad de público (Ibíd.). Así, en otra de las entrevistas, ${ }^{13}$ realizada a una pareja propietaria de uno de estos camiones, estos hacían referencia a ambos elementos, señalando que el pago por aparcar su foodtruck dentro de Palo Alto era de $650^{14}$ euros por el sábado y el domingo, y que la organización les impedía vender bebidas, ya que solo lo consiente a una conocida marca de cervezas que tiene mostradores dispuestos por todo el recinto. En este sentido, añadían que

[...] es un coñazo (sic) para el cliente y para nosotros... una putada (sic). En otras ferias que hemos estado hemos pagado solo $100 €$ de inscripción, este es el más caro de todos. Es un evento muy bueno para ellos [los organizadores] pero no tanto para nosotros [...] Todos pensamos lo mismo. Va bien, pero es muy caro. He hablado con los de Versolari y Boreal [otras de las food-trucks] y piensan lo mismo.

Inquiridos sobre si repetirían su experiencia, indicaban que

\footnotetext{
${ }^{13}$ Alfredo, argentino, trabaja como mozo en una compañía de transporte de obras de arte, y Núria, catalana, acaba de dejar su empleo en una empresa de show room, según ella, para "poder dedicarle más tiempo a la furgoneta". Según el comentario de Núria, "su objetivo era poder trabajar juntos y de forma autónoma, sin jefes ni dependiendo de empresas". Los nombres de todos los informantes, así como de las paradas y food-trucks, han sido cambiados para mantener el anonimato de los mismos.

${ }^{14}$ En la página web de Palo alto Market, las tarifas establecidas para este tipo de instalación oscilan entre los 330 y los 550 euros + IVA. Más información: www.paloaltomarket.com
} 
[...] en la anterior vez que estuvimos recuperamos la inversión, aunque no sacamos mucho más. Esta vez le vamos a dar otra oportunidad, pero luego ya veremos si volvemos [...] La gente de Versolari, por ejemplo, sí me ha comentado que han perdido en algunas ocasiones. Esto está bien, pero lo ideal sería que nos dejaran vender en la calle.

Abandonando esta área, y enfilando por Street market, se topa uno con una gran y diversa oferta de productos. La selección de lo que se exhibe y vende se realiza bajo un criterio que, como la propia Directora, Paula Mariscal, señala, no puede ser de otra manera que "personal y subjetivo [...] realizado sobre la base de que el proyecto tenga ambición y esté trabajado y tenga talento [...], que tenga salida en el mercado", ${ }^{15}$ aunque la propia página web de Palo Alto tampoco es mucho más explícita cuando cita que "la selección se hace atendiendo a criterios de calidad y sintonía con los conceptos y objetivos que definen la identidad de este mercado reservándose el derecho de la no aceptación por no cumplir dichos criterios". Estos criterios se amplían, también, a los food-truck donde, como me señaló la pareja anterior, "no cualquiera puede entrar, hay que tener características especiales, en tema de estética y gastronomía. Hay que ser vintage, tener el carnet de hipster". Nos encontramos aquí con una vinculación clara del concepto de distinción del que nos hablara Bourdieu ([1979] 1998), por cuanto son los organizadores del evento, recordemos miembros de una familia de la burguesía valenciana asentada en Barcelona (Escuela de Arte, 2000), quienes establecen estos criterios, poseedores como son de un alto capital cultural, simbólico y económico, y capaces, por tanto de ejercer el papel de dominadores a la hora del proceso de reproducción de la estructura social vigente. Esta característica se ve reforzada por algunas expresiones recogidas en las entrevistas, como aquel informante que señaló que el carácter de Palo Alto no podía ser de otra manera "siendo quienes son quienes lo organizan [...] burguesitos de Pedralbes que vienen a encanallarse al Poblenou".

Continuando por el mercado, en Street market es posible encontrar productos de lo más variado: ropa de segunda mano; libros, bicicletas hechas, en parte, de bambú; gorros y cintas para el pelo muy elaboradas; láminas, pinturas e, incluso, un zapatero artesanal y una barbería. Cada una de las ediciones se encuentra bajo el paraguas de una temática concreta (Happy Days, On the Road, Fashion Weekend o Beach Market, siempre en inglés). Sin embargo, y pese a la imagen que la propia organización se encarga de proyectar a través de los medios y las redes sociales, los individuos y grupos que pude observar en mis visitas a Palo Alto no me permitirían establecer un patrón o destacar alguna característica especial entre los mismos, aunque si tuviera que destacar alguna, podría citar la edad -en torno a los 30 años- como posible pauta. Si, por un lado, los vendedores y vendedoras de los diferentes tenderetes establecidos a lo largo y ancho del reciento mantienen cierta estética común -quizás ésta sí más cercana a las proyecciones de la organización-, por otro lado, esto no es así con respecto al público asistente, que podría trasplantarse a cualquier calle de la ciudad y pasar desapercibido. En definitiva, la diferenciación es absoluta, aunque como me indicó otra de las personas entrevistadas, el público "ahora está más mezclado, pero en un principio no... antes [Palo Alto] estaba pensado para publicistas, creativos, etc., ahora incluso aparece en la oferta de los turoperadores, lo que ha conseguido atraer a gran número de turistas".

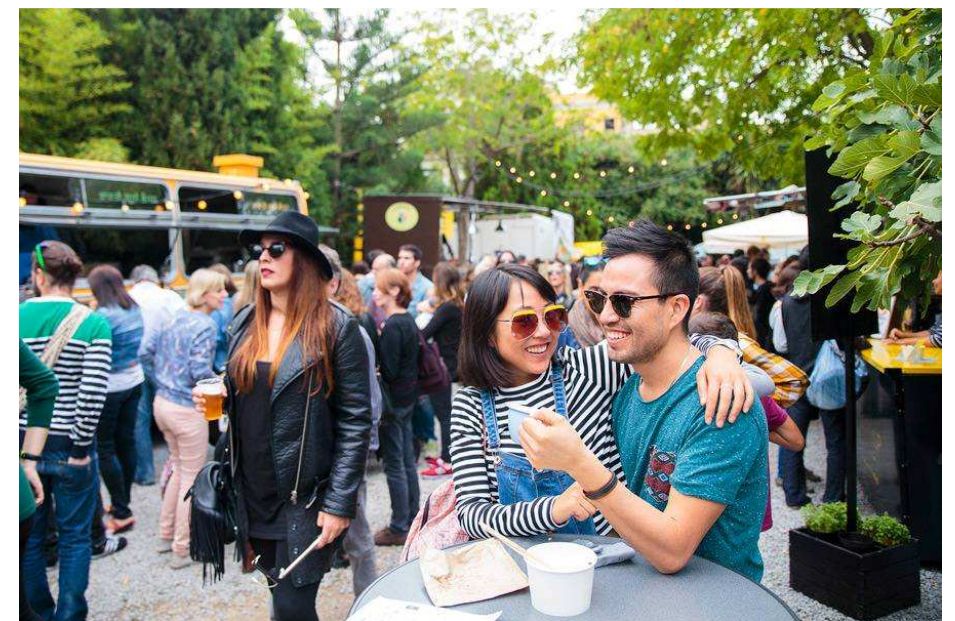

Foto 2.- Gente guapa y feliz, de diversos orígenes y colores, jóvenes siempre, vestidos a la moda y que se detienen en las paradas o conversan alegres y ajenos a las preocupaciones de la vida. Foto @PaloAltoMarket

\footnotetext{
${ }^{15}$ Traducción propia del catalán. Para más información ver: https://www.youtube.com/watch?v=TpTVIzmO3sc
} 
A este respecto, algunos de los comentarios obtenidos en algún diálogo informal con visitantes podrían añadir algo de luz sobre el éxito de un mercado como Palo Alto. Así, una chica de 34 años residente en Nou Barris, barrio popular del nordeste de la ciudad, me comentó que "vengo porque es como una revista..., vengo a ver a la gente, cómo viste, cómo se mueve... me tomo algo, y cuando la revista se ha acabado, me voy", a lo que añadía "los hay que vienen a pasear y a que les echen una foto, al postureo (sic)". En otra entrevista, dos estudiantes veinteañeras subrayaban que "nos gusta el ambiente, la música... el ambiente sobre todo". De este modo, la importancia de la imagen proyectada por Palo Alto como mecanismo de legitimación simbólica (Bourdieu, op. cit.) se presenta como uno de los factores más importantes a la hora de explicar el fenómeno de atracción con el que cuenta el mercado, pero también, como veremos a continuación, de la fuerte carga de autoexplotación -y por tanto de dominación- que es posible encontrar en el mismo.

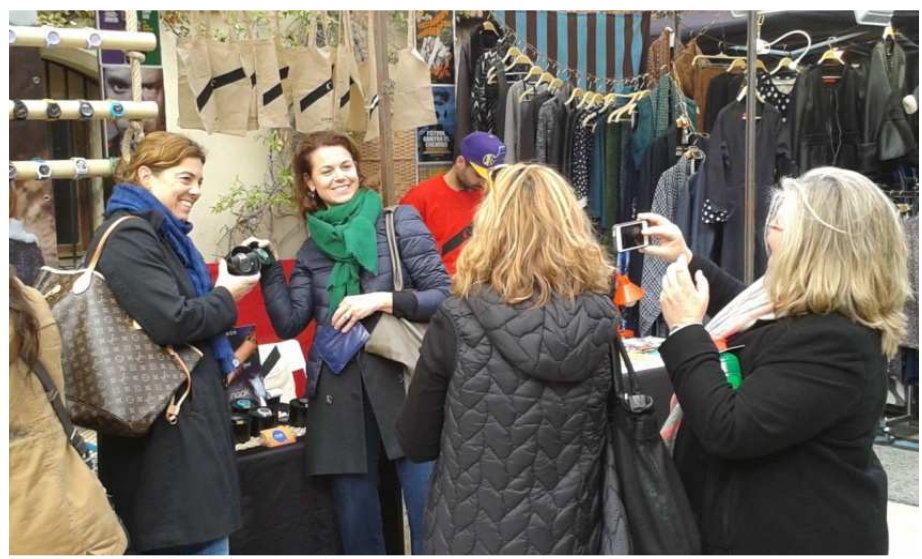

Foto 3.- Las fotografías con productos y los selfies en las calles del mercado son constantes y vendrían a afirmar la importancia de la imagen y el denominado postureo. Foto del autor.

Justo al comienzo de Street market se encuentra la Sala Funk, una pequeña sala de conciertos desde donde parte otra calle, Huerto street food, que cuenta con numerosas paradas de productos alimentarios desde kétchup ecológico a chocolates, garrapiñadas, pasteles caseros de sabores exóticos, muffins, donuts, etc.-. Huerto street, antes de volver a conectar con Street food, pasa por una zona de música al aire libre -la Terraza Buganvilla-, desemboca en una amplia zona de restauración y permite el acceso a dos grandes salas de venta dedicadas a productos específicos, Boheme Gallery y Design Gallery. Justo en la puerta de ésta última entrevisté a una artesana de 30 años que exhibía sus propios productos en Palo Alto, aunque mantiene su trabajo por cuenta ajena. Justamente, la artesana me comentó que evaluaba su presencia en Palo Alto como

[...] una plataforma para poder vender a aquellos que no tenemos una tienda física, como la mía que solo vendo online. Además, como evalúan tu producto antes de aceptarte, pues esto hace que todas las cosas que hay sean atractivas...,

a lo que añadía "a mí me merece la pena, es un sitio para darte a conocer [...], aunque sí es verdad que hay gente que gana mucho dinero y otros que pierden... yo, hasta ahora, no he perdido. Siempre he logrado recuperar la inversión". Esta artesana, asimismo, también ha sido testigo de ese cambio en el público asistente al mercado que señalábamos anteriormente. Así, explicaba que, al principio, "sí que parecía un sitio más elitista, más hipster, pero ahora no, es un ambiente familiar... también los productos son más variados", y preguntada sobre la rentabilidad de su presencia, afirmaba que "es verdad que la gente no compra mucho, quizás porque ahora ya ha perdido el carácter de novedad, es más conocido, no sé, es más difícil vender [...] No volveré inmediatamente, no tengo tiempo, tengo que trabajar y demás". Al extremo de las escasas ventas realizadas también se refería otra de las personas entrevistadas cuando afirmaba, "[yo no compro] nunca, aunque unas amigas mías sí que compraron algo una vez, un bolso".

Abundando sobre el volumen de ventas, se podría establecer la hipótesis que, debido al tipo de productos que se ofrecen, los precios no se encuentran al alcance de todo el mundo. En este sentido parecen incidir algunos de los comentarios encontrados en las redes sociales cuando subrayan que, los "precios [no son] nada populares", "la comida: fatal! cara y mal preparada", o "todo carísimo y espacio pequeño y apretado" (Facebook.com). Sin embargo, en la línea antes reseñada del mercado como acontecimiento inserto en la sociedad del espectáculo (Debord, [1964], 1995) una de las informantes me señaló que 
[...] un sitio como Palo Alto Market atrae a este tipo de gente por su música, su estilo..., no a comprar [...] yo tengo amigas que son las típicas que usan las redes sociales para enseñarle continuamente a la gente lo que están haciendo. Son majas, ¿eh? pero viven la vida a través de la imagen que proyectan.

O también como me relató Xavi, diseñador gráfico y pintor de unos 50 años y expositor en el mercado, "antes solo venían los pijos a picotear y tomar cañas, no a comprar nada, y nosotros estábamos como meros adornos decorativos"

El final de Street market enlaza con Buganvilla street, calle que debe su nombre al espectacular jardín vertical que cubre las paredes de una de las edificaciones, el cual fue diseñado originalmente por el artista Pepicheck Farriol, y que supone otro de los grandes atractivos del mercado (Sampedro, 2013). Esta última y recóndita calle también se encuentra repleta de tenderetes y paradas con productos, dando entrada, además, al antiguo estudio de Xavier Mariscal, hoy convertido en la Concept Gallery, donde normalmente se exponen mercancías relacionadas con la temática del evento -tablas de surf, cuando Beach Market, bicicletas de diseño, zapatos, etc.-, pero donde también es posible encontrar otro tipo de productos.

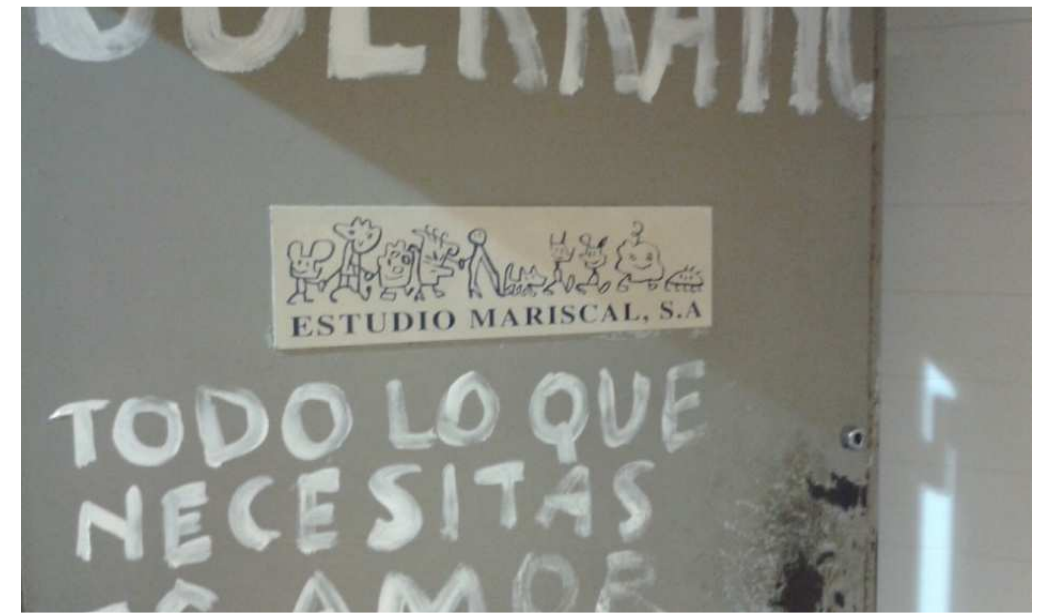

Foto 4.- Salida de Concept Gallery, antiguo estudio del diseñador Xavier Mariscal. Foto del autor.

Otra de las características de Palo Alto Market es que supone un espacio que no es únicamente rentabilizado por restauradores, artistas, diseñadores noveles o vendedores de productos exclusivos, sino que también es aprovechado, por parte de los organizadores, para la promoción de productos consolidados -marcas de cerveza, fabricantes de pastas y sémolas, etc. -y no tan consolidados- lácteos ecológicos, aplicaciones para móviles y tabletas y demás-. En este sentido, Palo Alto no dejaría de comportarse como un centro comercial "hecho con más cariño, [...] como si los detalles estuvieran más cuidados", tal y como resaltaba otra de las personas con las que hablé. Esta gran tienda al aire libre, verdadero parque temático del consumo, podría considerarse, de este modo, como una contemporánea institución total donde todas las rutinas "están administradas formalmente" (Goffman, [1961] 2001: 13), hecho que se manifestaría tanto por el control ejercido sobre el tipo de producto, visitante y expositor que es admitido en el interior del recinto, como por la gestión de cada uno de los aspectos más cotidianos de su interior (limpieza, emergencias, etc.). De hecho, otro de los informantes me relató la anécdota de que, cuando llueve de forma inesperada, la organización vende a los propios expositores plásticos impermeables a un precio de cinco euros, cuando el precio fuera del mercado es de solo uno.

\subsection{El exterior}

Tal y como se ha señalado en párrafos anteriores, Palo Alto Market se encuentra situado en el antiguo barrio industrial del Poblenou. Aunque la zona sigue manteniendo un marcado carácter popular, la renta familiar disponible viene aumentando sin cesar a lo largo de los últimos años, aproximándose a la media de la ciudad de Barcelona -pasando de 89,8 a 95,4 en tan solo dos años (Departament d'Estadística de l'Ajuntament de Barcelona)- y convirtiendo al Poblenou en un espacio de y para las clases medias (Mansilla, 2015). Prueba de las transformaciones que vienen ocurriendo en la zona es la celebración del propio 
mercado de Palo Alto, o de la aparición, sobre todo en la zona sur del barrio, de un denso entramado artístico y cultural que encuentra acomodo en antiguas instalaciones industriales y comerciales de bajo precio, dando lugar a asociaciones como Poblenou Crea! o Poblenou Urban District, colectivo que cuenta con el objetivo de "impulsar la oferta cultural y comercial de la zona y promover el Poblenou como el nuevo distrito de arte y creatividad de Barcelona". ${ }^{6}$ Aunque la relación entre incrementos del valor del suelo, desplazamientos socio-espaciales o la mercantilización del espacio con actividades de carácter cultural y artístico ha sido ampliamente estudiada (Zukin, 1987; Lloyd, 2002; Caulfield, 1989; Sequera, 2014, por citar solo algunas referencias), la complejidad de tal tarea escapa al alcance inicialmente previsto por la presente investigación. Sin embargo, eso no quita que sea posible determinar la cierta influencia, sobre todo a nivel simbólico, que Palo Alto Market mantendría a su alrededor.

Entre el influjo más directo podemos citar las iniciativas de carácter artístico que han aparecido en su contexto geográfico más inmediato. Así, durante el trabajo de campo, me fue posible observar, en una de mis esperas en la cola para poder entrar al recinto, distintos afiches que anunciaban una tienda de muebles de diseño vintage original bajo el nombre de PaloSantoShop, en clara alusión al nombre del mercado.

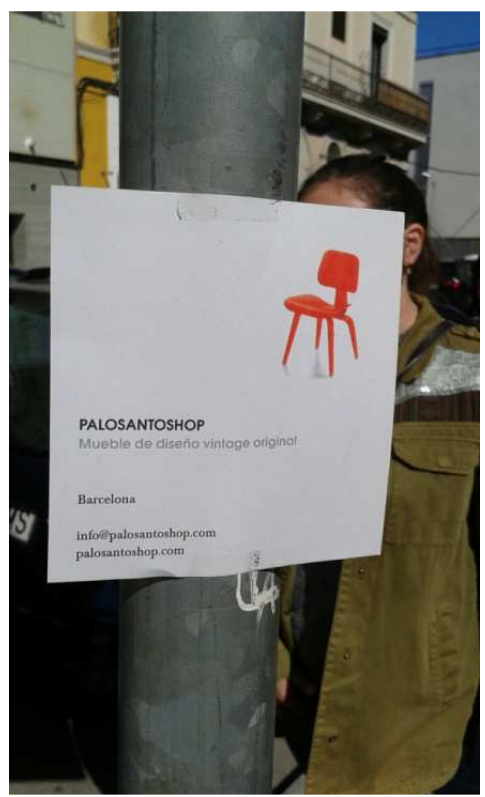

Foto 4.- Afiches colgados en posters y paredes anunciando los muebles de PaloSantoShop. Foto del autor.

Otra de las iniciativas artístico-culturales aparecidas al calor de Palo Alto es Rosa Palo Bcn. Este taller y galería, cuya designación también hace referencia al mercado, se encuentra situado a escasos metros de la entrada a Palo Alto, y es un proyecto personal de la pintora Inés Valls, que lo define como

[...] un esfuerzo por conciliar realmente vida familiar con sus hijos pequeños y su profesión [...] [y] un espacio multidisciplinar que se alquila íntegramente para eventos especiales de corta duración, ya sean Pop Ups, Showrooms o eventos privados singulares, siempre en el marco de un taller de pintor. El objetivo artístico de Rosa Palo Bcn es impulsar las obras de artistas organizando exposiciones bimensuales ${ }^{17}$

y que, como ella misma señala "lo he abierto porque era una oportunidad que se presentaba...".

Otra de las referencias que acusarían esta influencia por parte del mercado, sería el Bar-Restaurante Palo Verde, abierto durante 2016 en la Rambla del Poblenou, o el influjo que Palo Alto Market realiza sobre el tejido comercial y de servicios del barrio, hecho que se ve reflejado en una conversación informal que mantuve con un barbero cercano el cual, preguntado por su horario de apertura y cierre, me dijo: "De lunes a viernes y los fines de semana en que abre Palo Alto".

\footnotetext{
${ }_{17}^{16}$ Para más información ver: http://www.poblenouurbandistrict.com/

${ }^{17}$ Para más información ver: http://poblenoucrea.cat/es/rosa-palo
} 
Sin embargo, esta influencia no se encuentra exenta de conflicto, así como de la aparición de propuestas alternativas que, bajo formas paródicas, también han aparecido en el entorno de Palo Alto. Así, en diciembre de 2015 se llevó a cabo en el cercano barrio del Clot, un evento denominado Palo Bajo Merk'Art, acontecimiento que, como me relató Xavi, uno de los organizadores, perseguía ser

[...] contrapunto y contrapié a Palo Alto [...] que es un mercado al que yo acudo, y que está muy bien, en un lugar precioso, con una calidad musical excelente y que permite una oferta gastronómica muy alta y a gente como yo mostrar sus creaciones con una gran convocatoria, pero que es muy pijo, mientras que la idea de Palo Bajo era hacer una cosa más bohemia, a través de la guasa (sic) crear una plataforma que supusiese un Palo Alto para pobres.

\section{A MODO DE CONCLUSIÓN}

En los años 80, el Ayuntamiento de la ciudad de Barcelona puso en marcha un programa de restauración y rehabilitación de edificios denominado Barcelona posa't guapa. La mejora de la imagen de la ciudad ha formado siempre parte del conjunto de políticas urbanas impulsadas desde el Gobierno municipal, independientemente de su color político, persiguiendo, entre otras cuestiones, situar a Barcelona como referente para la atracción de capitales y como marca a nivel global (VVAA, 2004). En la misma línea podría situarse la campaña, en este caso impulsada por una asociación de comerciantes, Barcelona, la millor botiga del món, idea que, posteriormente, el Ayuntamiento hizo suya a través de la creación de unos premios, y cuyo objetivo era incidir en la consideración de la ciudad como un espacio de y para el consumo (Tello, 1993). De esta forma se ha promovido el paso de los barceloneses, así como los visitantes, de usuarios a consumidores de su espacio urbano, de forma que la aparición de mercados como Palo Alto Market no sería más que una nueva vuelta de tuerca a esta mercantilización, aunque bajo el prisma de conceptos novedosos como lo hipster, lo auténtico, la creatividad, la innovación o la oportunidad, en una evidente deriva postmoderna y elitista.

Sin embargo, si algo caracteriza a Palo Alto Market, como evento significativo es, por un lado, el protagonismo del propio espacio -el antiguo recinto industrial situado en el barrio del Poblenou donde se ubica- y el control ejercido por los organizadores sobre el contenido del mercado y, por otro, el énfasis dado al uso de cierto tipo de imágenes, así como a la construcción de narrativas de alto poder simbólico, que parecen convertir la visita a su recinto en una experiencia única vinculada a la sofisticación y al alto consumo. En definitiva, en su capacidad para crear capital simbólico y situarlo de forma privilegiada en ese espacio social que es la ciudad de Barcelona. O, visto de otra manera, por la forma en la que, mediante dispositivos simbólicos, ha sido capaz de encajar perfectamente dentro de la ideología hegemónica existente -la de la ciudad como elemento de consumo-, ocultando formas de dominación y explotación evidentes que, a veces, llegan incluso a convertir a los individuos en meros figurantes de un gran espectáculo, bajo la esperanza, no siempre fundada, de alcanzar algún tipo de capital, ya sea este económico o cultural. Restauradores y propietarios de food-trucks que no consiguen rentabilizar su presencia en el mercado; artesanos que compatibilizan varios trabajos y apenas recuperan la inversión realizada para promocionar sus productos; visitantes que realizan colas interminables y que pagan una entrada simplemente para que se les permita seguir consumiendo; precios inaccesibles para las rentas medias de la ciudad; fomento del individualismo consumista y relaciones sociales mediatizadas a través de la imagen, etc., son algunas de las prácticas que Palo Alto acoge en su interior.

No podemos olvidar, por último, el efecto que genera en su entorno más inmediato, el cual, a veces, se manifiesta como original alternativa que, mediante el uso de la ironía y el sarcasmo, enfrenta este enésimo eslabón de la Barcelona neoliberal contemporánea.

\section{BIBLIOGRAFIA}

BOURDIEU, P. ([1979] 1998). La distinción. Criterio y claves sociales del gusto. Madrid: Ed. Taurus.

BOURDIEU, P. ([1994] 1997). Razones prácticas. Sobre la teoría de la acción. Barcelona: Anagrama.

BRENNER, N., PECK, J. y THEODORE, N. (2015). "Urbanismo neoliberal. La ciudad y el imperio de los mercados". En OBSERVATORIO METROPOLITANO DE MADRID, El mercado contra la ciudad. Globalización, gentrificación y políticas urbanas (211-243). Madrid: Traficantes de sueños. 
CAPEL, H. (2013). La morfología de las ciudades. III Agentes urbanos y mercado inmobiliario. Barcelona: Ediciones del Serbal.

CARMAN, M. (2006). Las trampas de la cultura. Los "intrusos" y los nuevos usos del barrio de Gardel. Buenos Aires: Paidos.

CASTELLS, M. ([1972] 1974). La cuestión urbana. Madrid: Siglo XXI

CASTELLS, M. (1995). La ciudad informacional. Tecnología de la información, reestructuración económica y proceso urbano-regional. Madrid: Ed. Alianza

CAULFIELD, J. (1989). Gentrification and desire. Canadian Rev. Soc. \& Anth. / Rev. canad. Soc. \& Anth. 26(4), 617-632.

CHARNOCK, G. et at (2014). City of rents: The limits to the Barcelona model of urban competitiveness. International Journal of Urban and Regional Research, vol. 38.1,198-217.

DALMAU, D. (2016). La pulverización de una colonia obrera: un barrio bajo atrapado en una zona alta. En ARICÓ, G., MANSILLA, J. A. Y STANCHIERI, M. L. (coords.), Barrios Corsarios. Memoria histórica, luchas urbanas y cambio social en los márgenes de la ciudad neoliberal (77-100). Pol-len Edicions: Barcelona.

DEBORD, G. ([1964] 1995). La sociedad del espectáculo. Santiago de Chile: Ediciones Naufragio.

DELGADO, M. (2005). Elogi del vianant. Del 'Model Barcelona' a la Barcelona real. Barcelona: Edicions de 1984.

DELGADO, M. (2007). La ciudad mentirosa. Fraude y miseria del Modelo Barcelona. Madrid: Libros de la Catarata.

FABRE, J. y HUERTAS CLAVERIA, J. M. (1976). Tots els barris de Barcelona Vol. 1. Barcelona: Ed. 62.

GOFFMAN, E. (2001). Internados. Ensayos sobre la situación social de los enfermos mentales. Buenos Aires: Amorrortu Editores.

GONZÁLEZ, M. J. (1998). La cuestión urbana: Algunas perspectivas críticas. Revista de Estudios Políticos (Nueva época), no 101, 303-333.

GONZÁLEZ, S. y WALEY, P. (2012). Traditional Retail Markets: The New Gentrification Frontier? Antipode, vol. 45, 965-983.

GUANO, E. (2002). Spectacles of Modernity: Transnational Imagination and Local Hegemonies in Neoliberal Buenos Aires. Cultural Anthropology, vol. 17, №2, 181-209.

GUANO, E. (2004). The Denial of Citizenship: "Barbaric" Buenos Aires and the middle-class imaginary". En City and Society, Vol. 16, nำ1, 69-97.

GRAD, F. (2016). Mercados tradicionales: Lo local y lo global en experiencias de asimilación, acomodación y resistencia a la gentrificación en Madrid y Quito. Actas del Congreso Contested_Cities 2016, Universidad Autónoma de Madrid.

HACKWORTH, J. y SMITH, N. (2001). The changing state of gentrification. En Tijdschrift voor economische en sociale geografie, Vol. 92, Issue 4, 464-477.

HARVEY, D. (2007). Breve historia del neoliberalismo. Madrid: Akal.

HARVEY, D. (2007). Espacios del capital: Hacía una geografía crítica. Madrid: Akal.

HARVEY, D. (2008). París, capital de la modernidad. Madrid: Akal. 
HARVEY, D. y SMITH, N. (2005). Capital Financiero, Propiedad Inmobiliaria y Cultura. Barcelona: MACBA/UAB.

HERNÁNDEZ, A. (2014). Gentrificación comercial y mercados públicos: El Mercado de Santa Caterina, Barcelona". Working Papers Contested_Cities, 14017.

HERNÁNDEZ, A. y TUTOR, A. (2015). Espacio público: Entre la dominación y la(s) resistencia(s)". En ARICÓ, G., MANSILLA, J. A. Y STANCHIERI, M. L. (Coords.), Mierda de Ciudad. Una rearticulación crítica del urbanismo neoliberal desde las ciencias sociales (58-72). Barcelona: Pol-len Edicions.

INSTITUTO DE MERCADOS DE BARCELONA (2012). The markets of the mediterranean. Barcelona: IMB.

LEES, L., SLATER, T. y ELVIN W. (2008). Gentrification. Londres: Routledge.

LLOYD, R. (2002). Neo-Bohemia: Art and neighborhood redevelopment in Chicago. Journal of Urban Affairs, Vol. 24, № 5, 517-532.

MAKHLOUF, M. (2015a). Aproximaciones a la gentrificación en el Río de Janeiro de los megaeventos deportivos. Actores, discusiones y resistencias. En DELGADILLO, DÍAZ y SALINAS (Coord.) Perspectivas del estudio de la gentrificación en México y América Latina. Instituto de Geografía, México, D.F.: Universidad Autónoma de México (UNAM).

MAKHLOUF, M. (2015b). Movimientos vecinales y transformaciones urbanísticas. Una aproximación etnográfica al caso de la Barceloneta. En ARICÓ, G., MANSILLA, J. A. y STANCHIERI, M. L. (Coords.), Mierda de Ciudad. Una rearticulación crítica del urbanismo neoliberal desde las ciencias sociales (154-166). Barcelona: Pol·len Edicions.

MANSILLA, J. A. (2015). El triunfo de las clases medias. Dialéctica entre cambio social y urbanismo en el Poblenou, Barcelona. En Revista de Antropología Experimental, № 15, Universidad de Jaén, 121-139.

MASCARENHAS, G. (2010). Barcelona y Río de Janeiro: Diálogo entre modelos y realidades del llamado urbanismo olímpico. Biblio 3W. Revista Bibliográfica de Geografía y Ciencias Sociales, Universidad de Barcelona, Vol. XV, ํo 895 (12).

MASSEY, J. (2005). The Gentrification of Consumption: A View from Manchester. En Sociological Research Online, Vol. 10, Issue 2.

NEL·LO, O. y DONAT, C. (2014). Los efectos territoriales de la crisis económica en la región metropolitana de Barcelona. En Geografía de la crisis económica en España. Valencia: Universidad de Valencia, 565-608.

PORCER, S., SARASA S. y NAVARRO-VARAS, L. (2015) "Desindustrialización y crisis en la Barcelona postolímpica: hacía una ciudad dual?". En Actas de la International Conference on Regional Science, XLI Reunión de Estudios Regionales - AECR, noviembre de 2015, Facultad de Economía y Empresa Universitat Rovira i Virgili.

RECIO, A. (2009). La crisis del neoliberalismo. En Revista de Economía Crítica, ㄲo7, primer semestre, $96-$ 117.

RODRÍGUEZ, A. (2016). Los mercados de abastos: Nuevos límites de la gentrificación en Madrid. En Actas del Congreso Contested_Cities 2016, Universidad Autónoma de Madrid.

SEQUERA, J. (2014). Gentrificación en el centro histórico de Madrid: el caso de Lavapiés. En Rodrigo Hidalgo y Michael Janoschka (eds.), La ciudad neoliberal. Gentrificación y exclusión en Santiago de Chile, Buenos Aires, Ciudad de México y Madrid (233-255). Madrid: Traficantes de Sueños.

TATJER, M. (2006). La industria en Barcelona (1832-1992). Factores de localización y transformación en las áreas fabriles: del centro histórico a la región metropolitana. En Scripta Nova. Revista electrónica de geografía y ciencias sociales. Barcelona: Universidad de Barcelona, 1 de agosto de 2006, vol. X, núm. 218 (46). 
TELLO, R. (1993). Barcelona post-olímpica: De ciudad industrial a escenario de consumo. En Estudios Geográficos, Tomo LIV, n212, 507-520.

VVAA, (2004). Barcelona, Marca Registrada: Un model per desarmar. Barcelona: Virus Editorial.

WEBER, M. ([1922] 2002). Economía y sociedad. Madrid: Fondo de Cultura Económica de España.

ZUKIN, S. (2002). Gentrification: Culture and Capital in the Urban Core. En Annual Review of Sociology, Vol. 13. (1987), 129-147.

\section{FUENTES ELECTRONICAS}

AJUNTAMENT DE BARCELONA (2000). Modificació del PGM per la renovació de les zonesindustrials del Poblenou - Districte d'Activitats 22@BCN- [En línea, http://www3.amb.cat/normaurb2004/Docs/Normes mod/NUM-Barcelona-5.pdf] (Consulta: 15/02/2017)

AJUNTAMENT DE BARCELONA (2013). Ordenança de Terrasses" [En línea, http://ajuntament.barcelona.cat/ordenances/sites/default/files/pdf/bop2013-12-31 1.pdf] Boletín Oficial de la Provincia de Barcelona, 31/12/2013 (Consulta: 15/02/2017)

AJUNTAMENT DE BARCELONA (2015). Estadísticas de Turismo: Barcelona ciudad y entorno [En línea, http://professional.barcelonaturisme.com/imgfiles/estad/Est2015.pdf] (Consulta: 15/02/2017)

AJUNTAMENT DE BARCELONA (2015). Informe sobre la situación de la ciudad [En línea, http://premsa.bcn.cat/wp-content/uploads/2015/01/BalancAME 2014-v1.pdf] (Consulta: 15/02/2017)

ALTHUSSER, L. (1969). Ideología y aparatos ideológicos del Estado. Madrid: Universidad Complutense de Madrid [En línea, http://pendientedemigracion.ucm.es/info/eurotheo/e books/althusser/] (Consulta: 15/02/2017)

ANTEQUERA, J. (2015). Xavier Mariscal: "Ya nadie me llama, estoy sin trabajo, soy un mantero. En Revista Gurb [En línea, http://www.gurbrevista.com/2015/10/entrevista-a-xavier-mariscal/] (Consulta: 15/02/2017)

BENVENUTY, D. y GUERRERO, L. (2016) Poblenou, un barrio bajo presión. En La Vanguardia [En línea, http://www.lavanguardia.com/local/barcelona/20160731/403584148968/poblenou-un-barrio-bajo-

presion.html] (Consulta: 15/02/2017)

CARRIZOSA, S. (2016). El food-truck español se atasca. En El País [En línea, http://economia.elpais.com/economia/2016/07/05/actualidad/1467735191 810850.html] (Consulta: 15/02/2017)

COCOLA, A. (2015). Gentrificación y turismo en la ciudad contemporánea. Alba Sud [En línea, http://albasud.org/noticia/es/747/gentrificaci-n-y-turismo-en-la-ciudad-contempor-nea] (Consulta: 15/02/2017)

Come Calles (2015). Palo Alto Market, y ya van diez. En comecalles.com [En línea, http://comecalles.com/palo-alto-market-regresa-con-mas-innovaciones/] (Consulta: 15/02/2017)

DELGADO, M. (2014). Dominación, mediación y consentimiento. En El cor de les aparences [En línea, http://manueldelgadoruiz.blogspot.com.es/2014/12/dominacion-mediacion-y-consentimiento.html] (Consulta: 15/02/2017)

DOMÍNGUEZ SENSADA, M. (2012). Projecte Icària [En línea, http://projecteicaria.blogspot.com.es/] (Consulta: 15/02/2017)

EL MUNDO (2014). El Ayuntamiento de Barcelona cierra el mercadillo de Palo Alto por no disponer de permisos. En elmundoes línea, http://www.elmundo.es/cataluna/2014/12/07/54843563268e3e895a8b4577.html] (Consulta: 15/02/2017) 
ESCUELA DE ARTE (2000). Javier Marisca (Valencia, 1950) [En línea, http://www.escueladearte.com/actividades/motiva/Motiva2000/Conferencias/Mariscal.htm] (Consulta: 15/02/2017)

GALTÉS, M. (2016). Barcelona, cuarta ciudad más creativa en el mundo". En La Vanguardia [En Línea, http://www.lavanguardia.com/economia/20160724/403429954732/barcelona-cuarta-ciudad-mas-creativadel-mundo-diseno-bcd.html] (Consulta: 15/02/2017)

LLISTAR, D. (2015). De la Barcelona neoliberal a l'economia del comú. En elcritic.cat [En línea http://www.elcritic.cat/blogs/sentitcritic/2015/04/17/de-la-barcelona-neoliberal-a-leconomia-del-comu/] (Consulta: 15/02/2017)

MANSILLA, J. A. (2016) El turismo contra los barrios. En El País [En línea, http://blogs.elpais.com/seresurbanos/2016/09/turismo-contra-barrios.html] (Consulta: 15/02/2017)

MÓVIL, P. (2016) Así son los nuevos mercados: hacer la compra y quedarte de cañas. En El País [En línea, http://elpais.com/elpais/2016/07/18/tentaciones/1468829637 545466.html?por=carrusel] $\quad$ (Consulta: 15/02/2017)

SAMPEDRO, P. (2013) Plantas para curar plantas. En El País [En línea, http://blogs.elpais.com/alterconsumismo/2013/09/plantas-para-curar-plantas.html] (Consulta: 15/02/2017) 


\section{ANEXO FOTOGRÁFICO}

Mapa 1.- Localización del barrio del Poblenou en el marco de la ciudad de Barcelona. Google Map

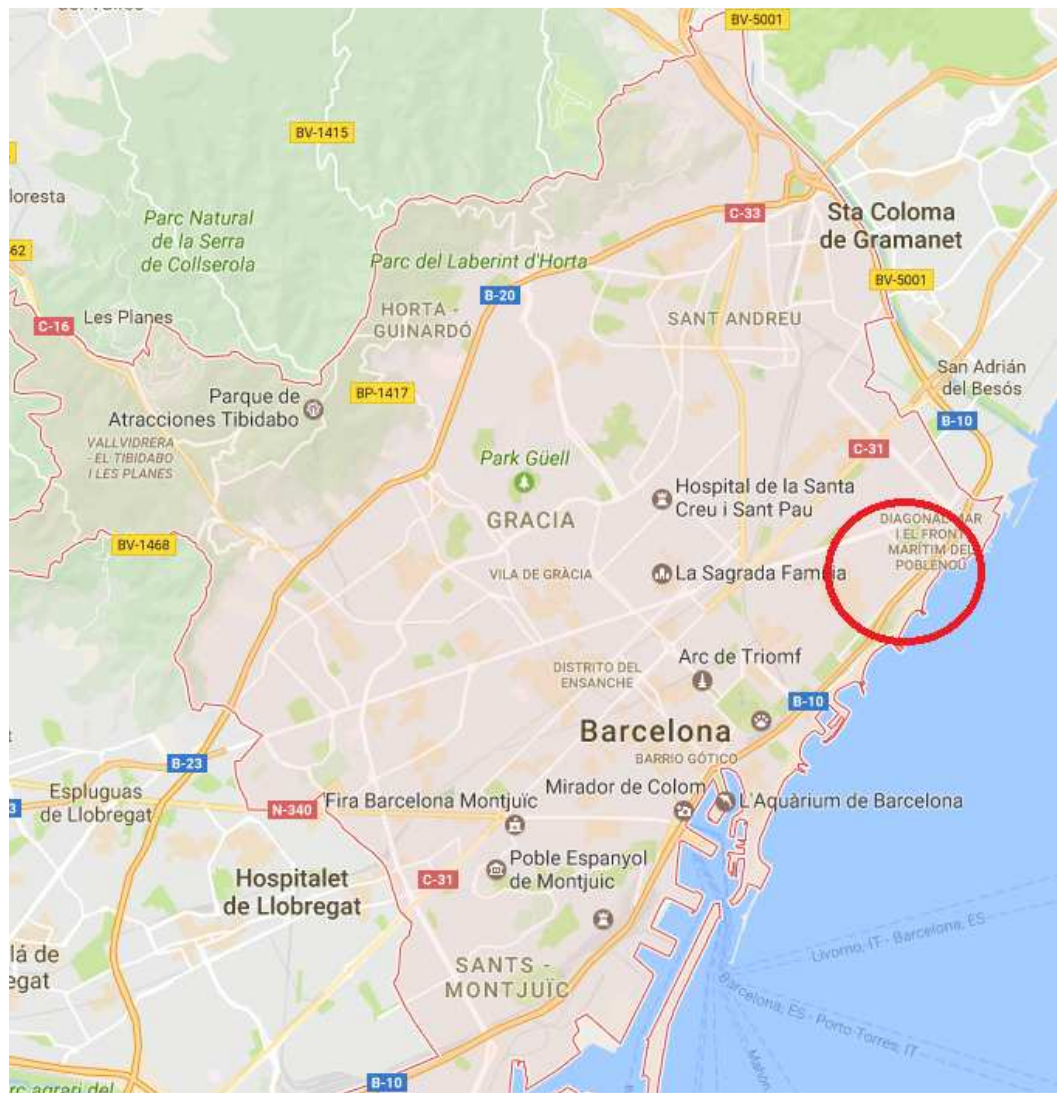

Mapa 2.- Palo Alto Market en el barrio del Poblenou. Google Map

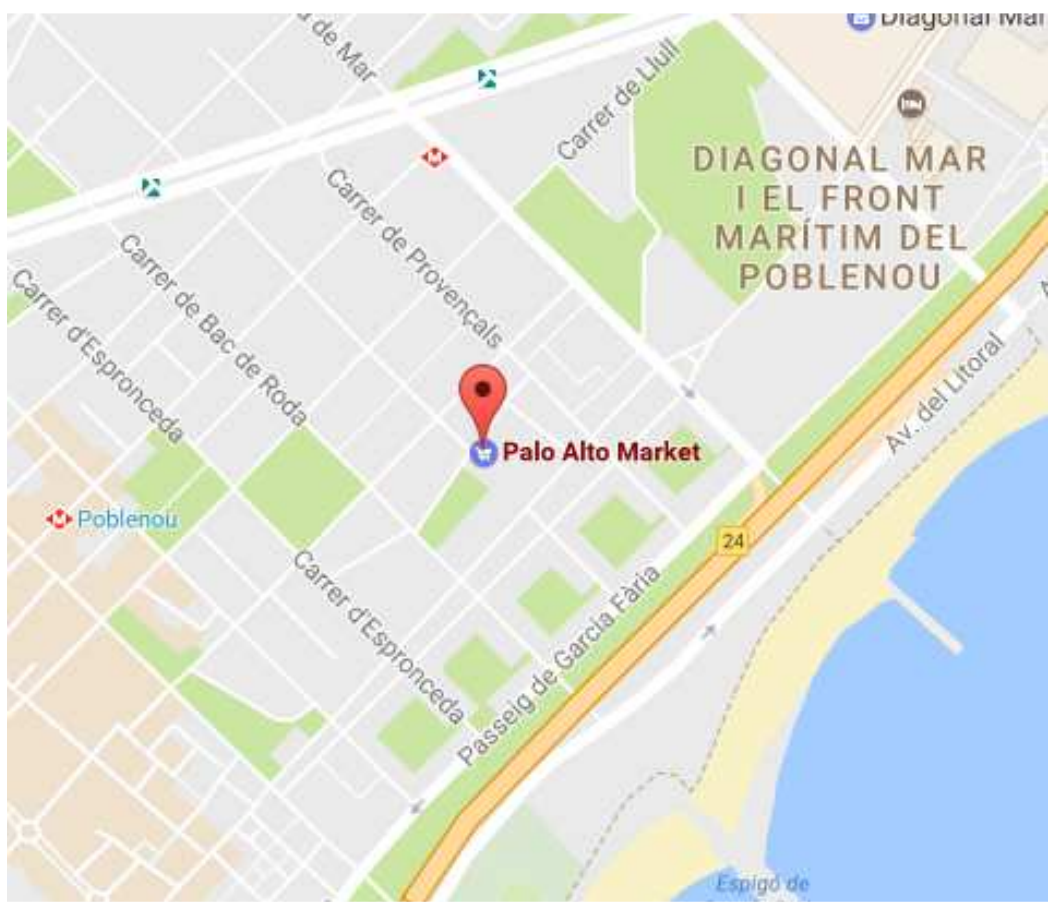


Mapa 3.- Interior de Palo Alto Market. Poblenourbandistrict.com

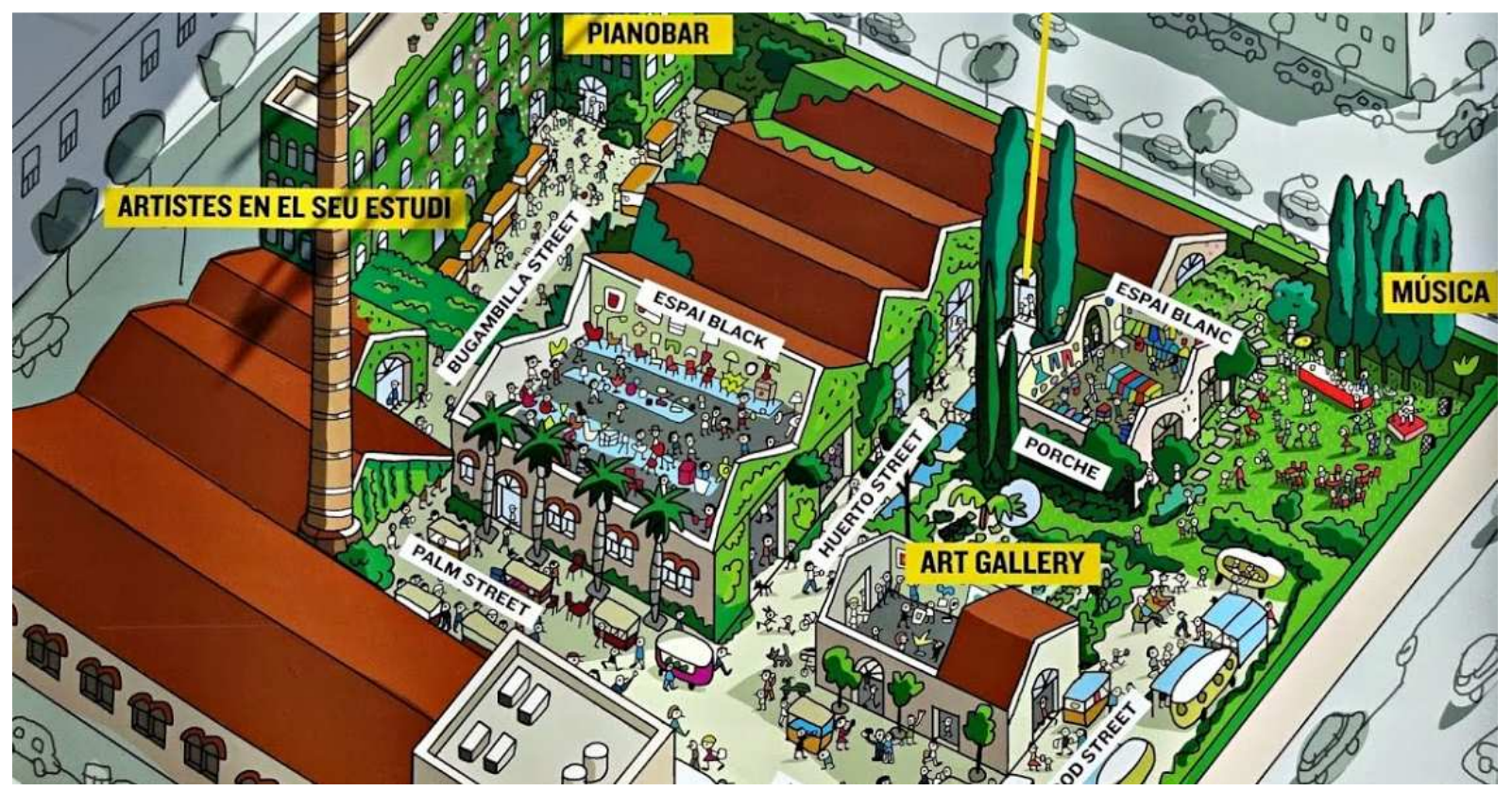

Foto 5.- Naves de Palo Alto desde la calle Ferrer (año 1990). Projecteicaria.blogspot.com

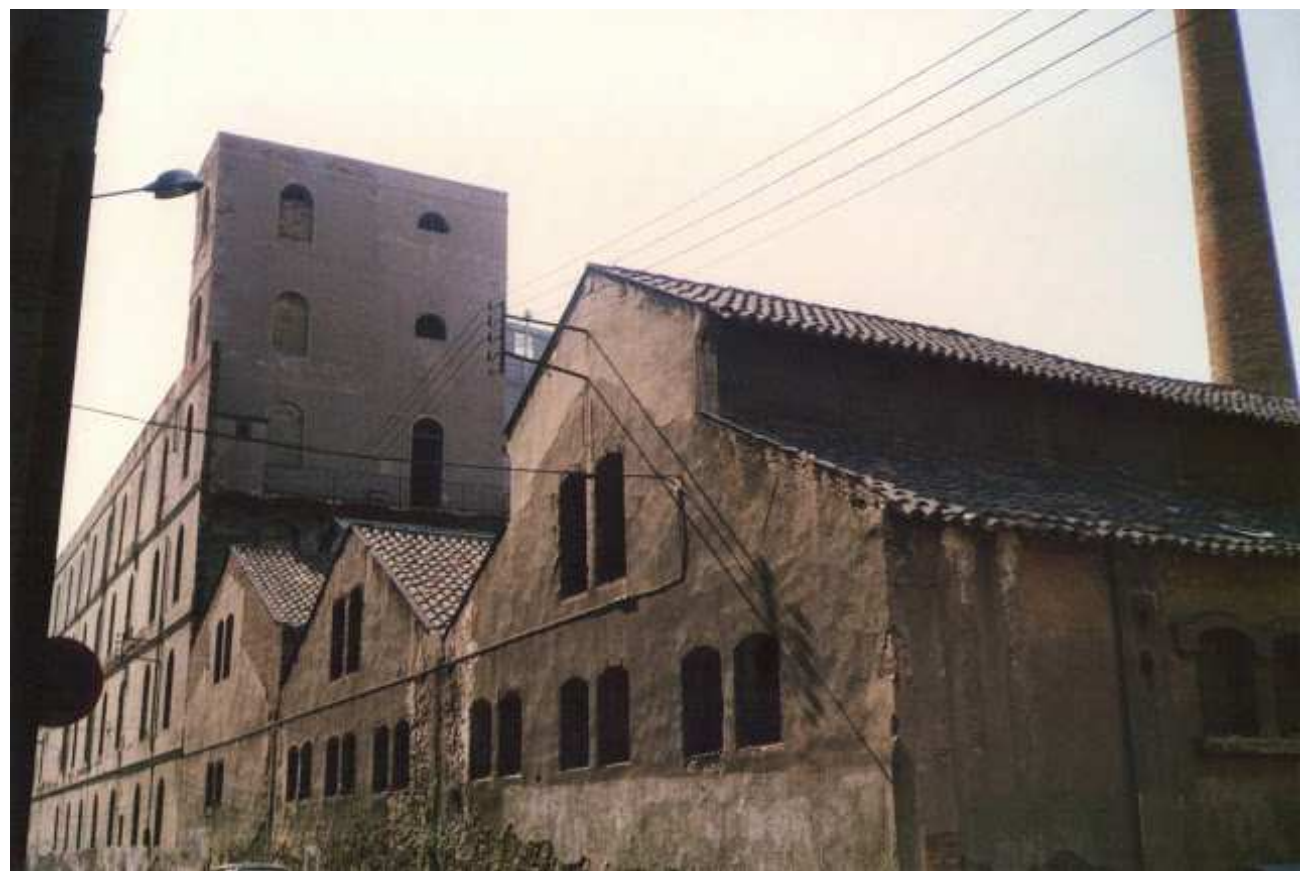

